\title{
CONTRIBUTION OF ENZYMATIC METHOD FOR ANALYZING SUCROSE AND STARCH IN TRADITIONAL CHINESE LIME- AND EARTH-BASED MORTARS
}

\author{
Kun Zhang ${ }^{\mathrm{a}, *, \odot, ~ S h i q i a n g ~ F a n g ~}{ }^{\mathrm{b}}$, Xin Mao ${ }^{\mathrm{c}}$ and Bingjian Zhang ${ }^{\mathrm{b}, \mathrm{d}}$ \\ ${ }^{a}$ School of Cultural Heritage, Northwest University, Xi'an, China \\ ${ }^{\mathrm{b} S} \mathrm{School}$ of Arts and Archaeology, Zhejiang University, Hangzhou, China \\ 'Department of Chemistry, National University of Singapore, Singapore, Singapore \\ ${ }^{d}$ Department of Chemistry, Zhejiang University, Hangzhou, China
}

Recebido em 30/01/2020; aceito em 09/04/2020; publicado na web em 04/06/2020

\begin{abstract}
Brown sugar and sticky rice were frequently used as organic additives in Chinese mortars. This study applied enzymatic spectrophotometric methods to identify sucrose and starch contents in traditional Chinese lime- and earth-based mortars. The focus was to understand and evaluate the qualitative detection capacity of enzymatic method in mortars, by first applying the method on a series of lab-prepared mortar specimens with specific amounts of brown sugar and sticky rice addition, then on historic mortar samples suspected to contain brown sugar and sticky rice. The potential contribution and limitations of enzymatic method in analysis of sucrose and starch in mortars was compared with other common available analytical methods. The results suggested that for lab-prepared brown sugar mortar specimens, enzymatic method was more sensitive and exclusive than chemical method, and particularly had higher detection capacity in lime mortars. For simulated mortars with sticky rice addition, enzymatic method showed no distinct detection capacity differences among the studied inorganic binders and comparing with chemical methods was more sensitive in earth-based mortars. Enzymatic analysis on historic mortar samples was able to distinguish some false-positive results from the chemical and FTIR analysis, which was then corroborated by SEM.
\end{abstract}

Keywords: mortar; analysis; sucrose; starch; enzymatic method.

\section{INTRODUCTION}

Mortar as one of the important components of architecture, possesses many functions including to bond masonry units together, to coat external and internal façades and to decorate. Since the $19^{\text {th }}$ century, the appearance and development of Portland cement gradually and eventually replaced most traditional mortars, ${ }^{1}$ due to its shorter setting time and higher mechanical strengths. However, the use of cement in fields of conservation and restoration of historic buildings was repeatedly denied because of unsatisfying compatibility problems..$^{2-5}$ Therefore, identification of historic construction materials including traditional mortars became significant in understanding the traditional mortar recipes and craftsmanship.

Among many ways to improve mortar qualities, organic additives were commonly added to try to modify the plastic properties of fresh mortar and/or to enhance the hardened mortar's performances. For example, the addition of oil, wine, hogs' lard and figs in lime was already described, among the most known and celebrated texts of technical literature of the Greek and Roman culture that still survives, by Vitruvius ${ }^{6}$ and Plinius. ${ }^{7}$ The use of natural organic additives in ancient Chinese mortars were accounted in numerous historic records, among which sticky rice and brown sugar were frequently applied. According to literature records, sticky rice along with brown sugar were usually added in lime, earth and "tabia" (mixture of lime and earth) to build forts and vernacular dwellings in eastern and southeastern China. ${ }^{8-12}$ Archaeological evidences also revealed the presence of starch (probably from sticky rice) ${ }^{13-16}$ and sugars ${ }^{13,15,17}$ in numerous historic monuments across China.

Methods of analyzing sucrose or reducing sugars in lime mortars include Benedict's reaction, ${ }^{15,17}$ sulphuric acid-phenol method, ${ }^{18}$ IR spectroscopy, ${ }^{15,17}$ etc. Among the methods of starch analysis in

*e-mail: kun_zhang1989@hotmail.com mortars, the most simple, direct and fast one was the classic chemical method using iodine-potassium iodide reagent. Other methods of analyzing starch in lime mortars include starch grain analysis, ${ }^{19}$ FTIR, ${ }^{14,15,17}$ TG-DSC, ${ }^{14,16}$ etc. Moreover, although methods such as GC-MS ${ }^{20-22}$ could have higher sensitivity and precision in saccharide analysis, it is labor intensive and time consuming due to complicated procedures. This study attempts to apply enzymatic methods for faster and simpler sucrose and starch analysis and evaluate its potential contribution and limitations as a complementary analysis method of organic additives in historic mortars.

\section{EXPERIMENTAL}

\section{Reagents}

\section{Chemical methods}

Reagents for analyzing reducing sugar were analytical-grade sodium citrate $\left(\mathrm{C}_{6} \mathrm{H}_{5} \mathrm{Na}_{3} \mathrm{O}_{7} \bullet 2 \mathrm{H}_{2} \mathrm{O}\right.$, Sinopharm Chemical Reagent, CAS no. 6132-4-3), anhydrous sodium carbonate $\left(\mathrm{Na}_{2} \mathrm{CO}_{3}, 99.8 \%\right.$, Sinopharm Chemical Reagent, CAS no. 497-19-8), anhydrous cupric sulphate $\left(\mathrm{CuSO}_{4}, 99.0 \%\right.$, Sinopharm Chemical Reagent, CAS no. 7758-98-7) and deionized water. Reagents for analyzing starch were analytical-grade potassium iodide (KI, 99.0\%, Sinopharm Chemical Reagent, CAS no. 7681-11-0), iodine $\left(\mathrm{I}_{2}, 99.8 \%\right.$, Sinopharm Chemical Reagent, CAS no. 7553-56-2) and deionized water. Benedict's solution and iodine-potassium iodide solution were prepared according to Fang et al. 2014. ${ }^{17}$

\section{Enzymatic methods}

Reagents for enzymatic analysis on sucrose were assay kits of Enzytec Fluid Sucrose (incl. Glucose) (R-Biopharm, E5180) and Enzytec Fluid D-Glucose (R-Biopharm, E5140), deionized water, hydrochloric acid $(\mathrm{HCl})$ and sodium hydroxide $(\mathrm{NaOH})$. Reagents for 
enzymatic analysis on starch were assay kit of R-Biopharm Enzytec Starch (R-Biopharm, E1268), deionized water, analytical-grade hydrochloric acid ( $\mathrm{HCl}, 36.0-38.0 \%$, Sinopharm Chemical Reagent, CAS no. 7647-01-0), sodium hydroxide ( $\mathrm{NaOH}, 96.0 \%$, Sinopharm Chemical Reagent, CAS no. 1310-73-2), DMSO $\left(\mathrm{C}_{2} \mathrm{H}_{6} \mathrm{OS}, 99.0 \%\right.$, Sinopharm Chemical Reagent, CAS no. 67-68-5) and ethanol $\left(\mathrm{C}_{2} \mathrm{H}_{6} \mathrm{O}\right.$, 95.0\%, Sinopharm Chemical Reagent, CAS no. 64-17-5).

\section{Lab-prepared mortar specimens}

To test the detection limit as well as credibility of enzymatic method, brown sugar and sticky rice mortar specimens were prepared. According to literature records, these two saccharides were commonly added in lime, tabia as well as in earth, therefore three series of mortars with different inorganic binders were prepared: hydrated lime, hydrated lime+ earth $(1: 1-w / w$, to simulate a simple tabia recipe) and earth alone.

\section{Raw materials}

Materials used for the mortar specimens were analyticalgrade calcium hydroxide $\left(\mathrm{Ca}(\mathrm{OH})_{2}, 95.0 \%\right.$, Sinopharm Chemical Reagent, CAS no. 1305-62-0), earth, deionized water, sticky rice (Jiulihu Food Co. Ltd.) and brown sugar (Jiulihu Food Co. Ltd.) bought from local supermarket in Hangzhou (Zhejiang province). According to nutritional composition provided by the manufacturer, the carbohydrate content in brown sugar is $93.5 \%-\mathrm{w} / \mathrm{w}$, and that in sticky rice is $77.5 \%-\mathrm{w} / \mathrm{w}$.

The earth used in this study was taken from the subsoil layer in Zhejiang province (eastern China). It was first crushed and sifted by 100 -mesh sieve, then dried under $100{ }^{\circ} \mathrm{C}$ in baking oven for 48 hours. X-ray diffraction analysis (XRD) was conducted on mortar sample powder using a PANalytical X' pert $^{3}$ Powder X-ray diffractometer (PANalytical, Netherlands), with $\mathrm{Cu}-\mathrm{K} \alpha$ radiation $(\lambda=1.540598 \AA), 2 \theta$ range $5-90^{\circ}$, step scan $0.01^{\circ}$, scan speed $10^{\circ}$ $\mathrm{min}^{-1}$, at $40 \mathrm{kV}$ and $100 \mathrm{~mA}$. The pattern (Figure 1) was reported as intensity (a.u.) vs $2 \theta\left(^{\circ}\right)$, and the result indicates that the earth used in the present study contains major quantity of quartz and traces of muscovite and hematite.

\section{Specimen preparation}

The organic additives were added in the form of sticky rice porridge and brown sugar solution. Sticky rice porridge was prepared by first adding sticky rice in deionized water in the proportion of 1:9-w/w, then cook the porridge for 4 hours in an electrical cooker. Water was constantly replenished during cooking to keep the original liquid volume. Then the broken rice grains were filtered out by gauze, keeping only the liquid part as the sticky rice porridge, which is considered as " $10 \%-\mathrm{w} / \mathrm{w}$ " sticky rice porridge. Such porridge was further respectively diluted 2.5, 10, and 40, 167, 667 and 2500 times with deionized water to make sticky rice porridge of 6 different concentrations $(4,1,0.25,0.06,0.015$ and $0.004 \%-\mathrm{w} / \mathrm{w})$. The actual sticky rice content in the " $10 \%-\mathrm{w} / \mathrm{w}$ " sticky rice porridge was estimated by drying the porridge in oven for 48 hours at $80^{\circ} \mathrm{C}$, and the weight of the dried solid was measured to account for $8.6 \%$ - w/w of the original porridge. The loss of sticky rice content was probably caused by the filtered-out broken rice grains. Moreover, considering the $77.5 \%$-w/w carbohydrate content in sticky rice (see nutritional composition in Raw materials section), the approximate starch contents in the sticky rice porridge are 2.67, $0.67,0.17,0.04,0.01$ and $0.002 \%-w / w$. Brown sugar solution was prepared by directly dissolving brown sugar in deionized water at 6 different concentrations $(4,1,0.25,0.06,0.015$ and $0.004 \%-\mathrm{w} / \mathrm{w})$, and since brown sugar contains $93.5 \%$ carbohydrate by weight (see nutritional composition in Raw materials section), the approximate sucrose contents in the mixing water of brown sugar mortar specimens are $3.74,0.935,0.234,0.056,0.014$ and $0.003 \%-\mathrm{w} / \mathrm{w}$.

The sticky rice porridge (brought to room temperature) and brown sugar solution were respectively mixed with the inorganic binders (hydrated lime, hydrated lime+ earth $(1: 1-w / w)$ and earth alone), with a constant mixing water/ binder ratio of 0.8 . In addition, reference mortars with no organic additives were also prepared. The mortar mixes were poured in into plastic disc molds with diameter of $5 \mathrm{~cm}$ and height of $1 \mathrm{~cm}$ and cured in lab $\left(\sim 25^{\circ} \mathrm{C}\right.$ and $\left.\sim 50 \% \mathrm{RH}\right)$ for 3 months before analyses.

\section{Historic mortar samples}

Apart from lab-prepared mortar specimens, Chinese historic mortar samples were also analyzed in the present study. Table $1 \mathrm{~S}$ shows information of the 45 historic mortar samples with different inorganic binders (lime, tabia (lime+ earth) and earth), and Figure 1S shows the distribution of the 9 provinces from which the samples were collected.

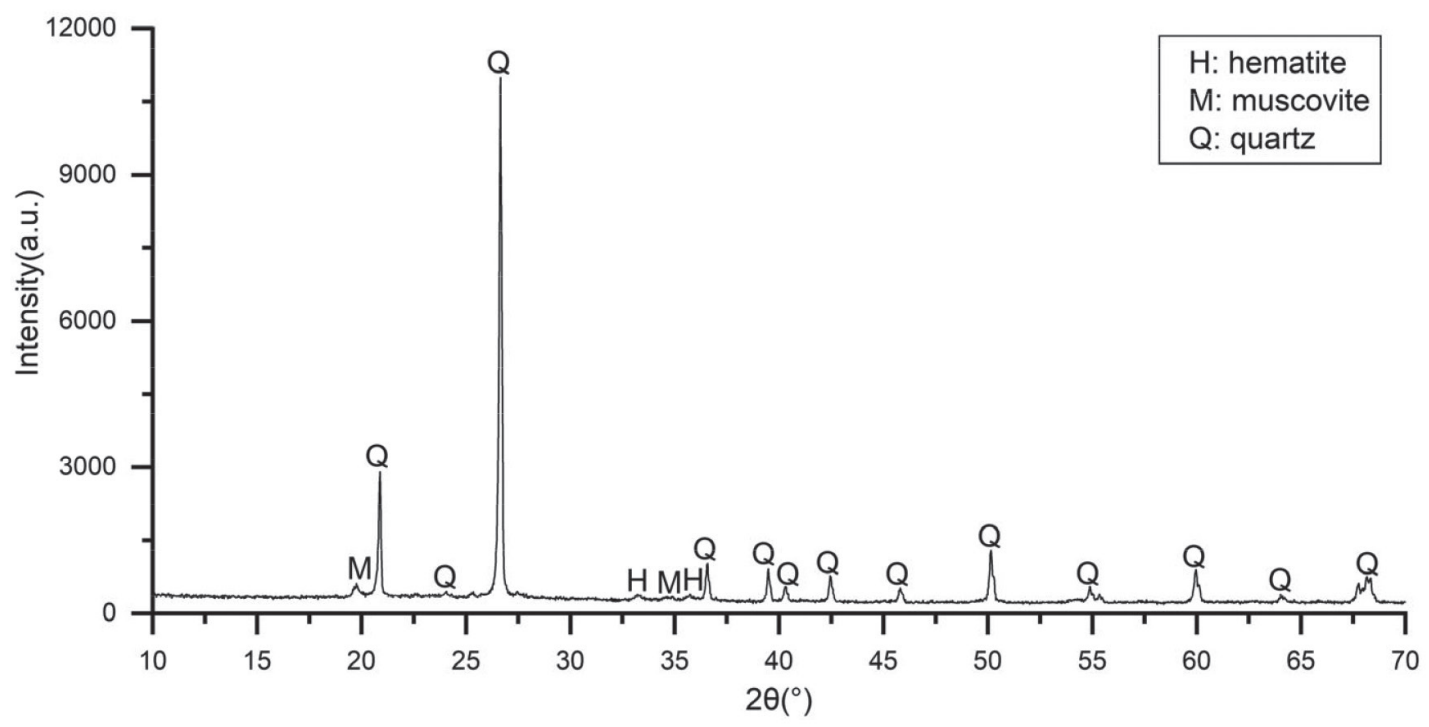

Figure 1. XRD pattern of earth used in the present study 


\section{Methods}

\section{Chemical methods}

Reducing sugars and starch in lab-prepared mortar specimens and historic mortar samples were analyzed using Benedict's solution and iodine-potassium iodide solution, according to procedures in Fang et al. $2014 .{ }^{17}$

\section{FTIR transmission spectroscopy}

FTIR in transmission mode was performed using a Thermo Fisher Scientific Nicolet iS50 FTIR Spectrometer (Thermo Fischer Scientific Inc., U.S.A.). The samples taken from the mortar bulk, as well as the raw materials were ground into fine powder and subsequently analyzed as $\mathrm{KBr}$ pellets (wavenumber $4000-400 \mathrm{~cm}^{-1}$, resolution $4 \mathrm{~cm}^{-1}, 32$ scans). The spectra were reported as transmittance (a.u.) vs wavenumber $\left(\mathrm{cm}^{-1}\right)$.

\section{Enzymatic methods}

Principles and procedures of sucrose and starch analysis adapted from the assay kit technical sheets are shown in Figures 2 and 3. For sucrose analysis, the sample was first hydrolyzed by $\beta$-fructosidase to release D-glucose; then hexokinase catalyzes the D-glucose by adenosine triphosphate (ATP) to form glucose-6phosphate (G-6-P); glucose-6-phosphate is oxidized in the presence of nicotinamide adenine dinucleotide $\left(\mathrm{NAD}^{+}\right)$by glucose-6-phosphate dehydrogenase. The arising NADH from the last step was determined spectrophotometrically at $340 \mathrm{~nm}$ by a UV-Vis spectrophotometer
(UV-1800PC, Mapada, China) and serves as a measure of the glucose6-phosphate formed from glucose. It should be noted, however, that if free glucose was present in solution, it would also be detected. Therefore, in order to confirm the presence of sucrose, the free glucose in samples should be additionally analyzed, and the corresponding glucose response should be subtracted from the total sucrose response, thus leaving only the sucrose response.

For starch analysis, the sample was first washed with $85 \%$ $\mathrm{v} / \mathrm{v}$ ethanol to remove low-molecular weight carbohydrates, then solubilized in dimethyl sulfoxide (DMSO) and hydrochloric acid $(\mathrm{HCl})$; the $\alpha$-1,4- and $\alpha$-1,6-glucosidic bonds in starch were hydrolyzed by amyloglucosidase (AGS) to form glucose; using hexokinase (HK), glucose-6- phosphate dehydrogenase (G6P-DH) and nicotinamide-adenine dinucleotide phosphate (NADP), the glucose formed was subsequently transformed by the reactions catalyzed by these enzymes to form reduced nicotinamide-adenine dinucleotide phosphate (NADPH), which is then measured at $340 \mathrm{~nm}$ by spectrophotometer. The absorbance of the NADPH is used to calculate the amount of starch in the sample.

Although the applied enzymatic method could estimate the quantitative sucrose and starch content in given solutions, as a first step the present study focuses rather on the understanding and evaluation of the qualitative detection capacity of such method in mortars, starting with a series of lab-prepared mortar specimens with specific amounts of brown sugar and sticky rice addition, then on historic mortar samples suspected to contain brown sugar and sticky rice. Therefore, the results of enzymatic methods in this study were presented as positive (“+”) or negative (“-”) responses basing

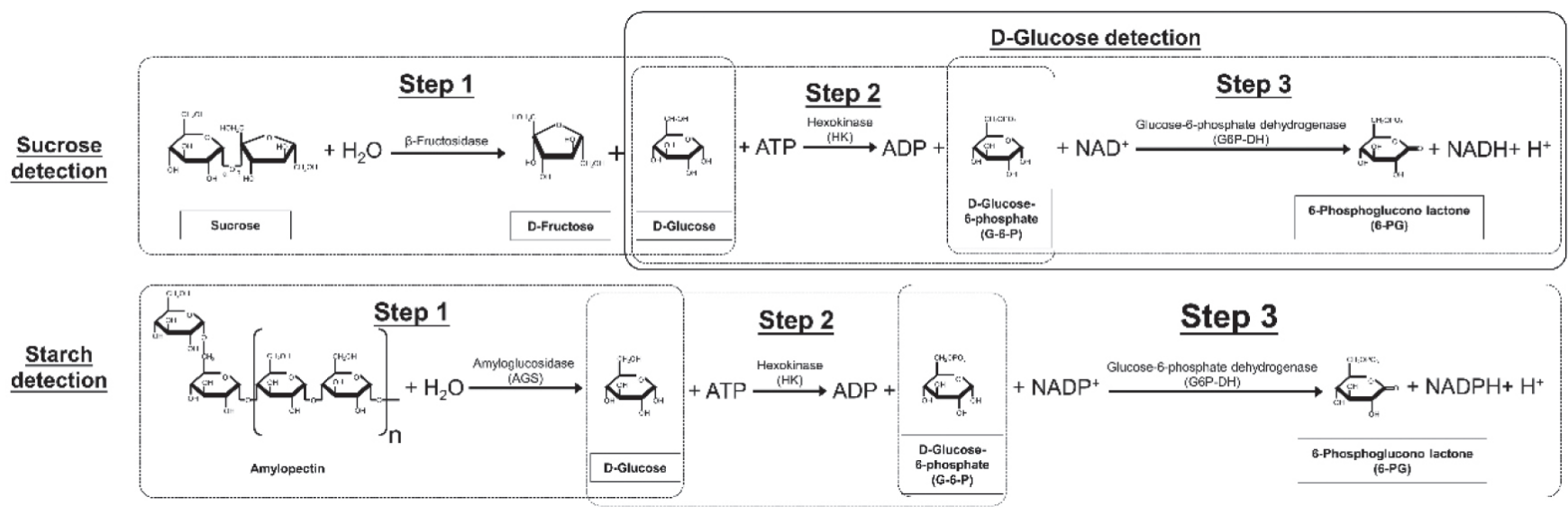

Figure 2. Principles of enzymatic methods for sucrose, starch and D-glucose analysis

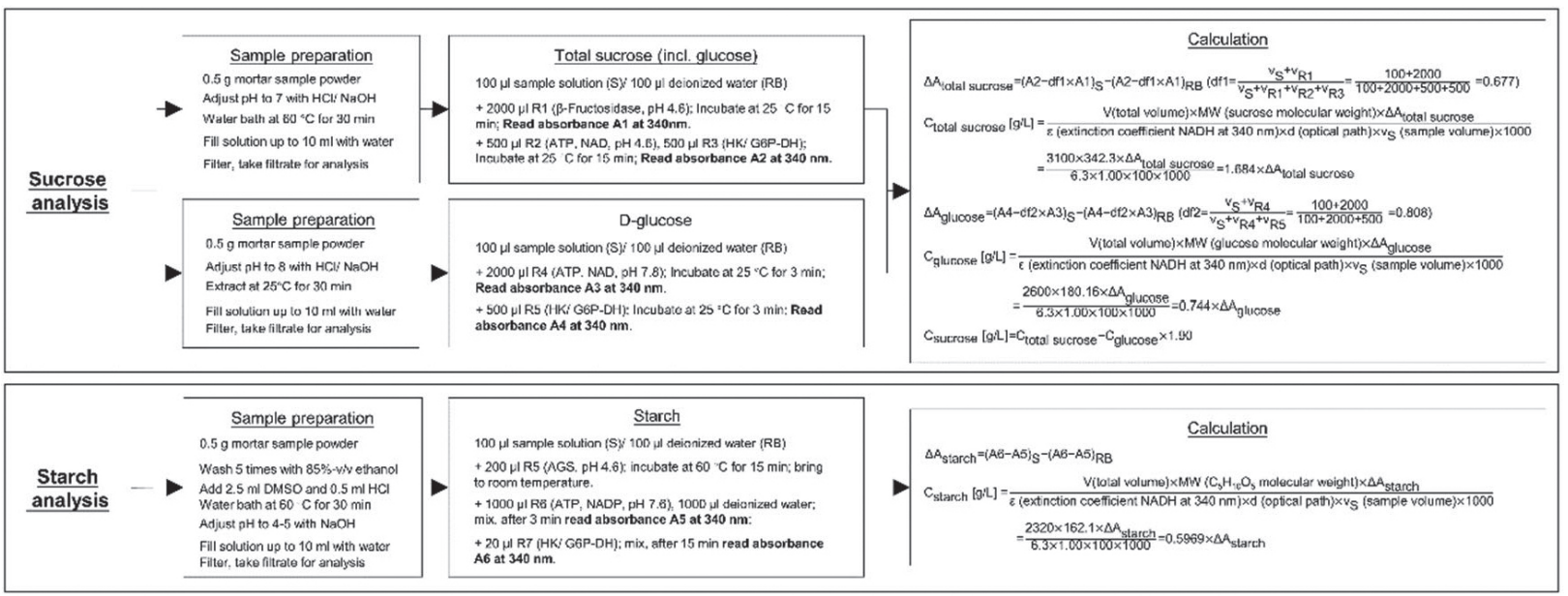

Figure 3. Procedures of enzymatic methods for sucrose, starch and D-glucose analysis 
upon the calculation of sucrose and starch contents in mortar sample solutions. The credibility of the quantitative aspects of the method, however, shall be subject to further study.

\section{Scanning Electron Microscopy}

The morphology of the internal bulk of different mortars was observed by a field-emission scanning electron microscope (Sirion100, FEI, Netherlands) operated at $15 \mathrm{keV}$ acceleration voltage.

\section{RESULTS AND DISCUSSION}

\section{Lab-prepared mortar specimens}

\section{Chemical methods}

Results of chemical methods on simulated mortars are shown in Figure 4. Chemical analyses on simulated brown sugar mortars with inorganic binders of lime and lime+earth was able to detect brown sugar addition above $1 \%$, while for the earth mortar it was $4 \%$. The shortcoming of the chemical method for sucrose analysis is that Benedict's reaction could only indicate the presence of reducing sugars (e.g. glucose, fructose, galactose, lactose, maltose) in solution, yet it could not effectively distinguish among the reducing sugars, nor could it specify which non-reducing sugars produced them.

As for the simulated sticky rice mortars, starch could be identified even when only $0.004 \%$ sticky rice was present. Such results showed that reaction between starch and iodine-potassium iodide solution was quite exclusive and sensitive in lime mortars. Yet when earth is present, the detection capacity was drastically impaired, with percentages raising to 4 and $1 \%$ for lime+earth and earth mortars, respectively, probably due to the adsorption of polysaccharides onto the clay particles in earth.

\section{Enzymatic methods}

Results of enzymatic analyses on simulated brown sugar and sticky rice mortars are shown in Table 1. Enzymatic analysis on simulated brown sugar mortars was able to identify sucrose in lime mortars with brown sugar addition above $0.06 \%$; as for the earthbased mortars (lime+ earth and earth alone) the percentages were both $0.25 \%$. Despite that the detection capacity was lower in earth-based mortars, the enzymatic method was more sensitive compared with the chemical method $(1,1$, and $4 \%)$. Moreover, chemical analyses could only indicate the presence of reducing sugars, while enzymatic tests measure sucrose specifically with the hexokinase reaction if samples contain only sucrose. Although the $\beta$-fructosidic bonds in oligosaccharides of the raffinose type could also be hydrolyzed by $\beta$-Fructosidase, the reaction will take on more slowly than sucrose. For sticky rice mortars the enzymatic method was able to detect sucrose in all mortars with brown sugar addition above $0.25 \%$. Compared with the chemical method results, the enzymatic analysis was less sensitive in mortars with lime as the sole binder $(0.004 \%$ by chemical method), but more sensitive in mortars containing earth (4 and $1 \%$ by chemical method).

\section{Historic mortar samples}

\section{Chemical methods}

Chemical methods were applied on the 45 historic mortar samples, and 11 samples from 5 provinces gave positive results (Table 2 and Figure 5). It should be noted that the tabia mortar sample from Tiger Hill Pagoda - with possible presence of sugar - contained plant stems (Figure 2S). Although the examined mortar powder was carefully separated from the plant stems and passed through sieve, since Benedict's reaction could only indicate the presence of reducing sugars, the positive result of such sample may also have been brought by the hydrolyzed residual plant stem powder in the mortar. Therefore,

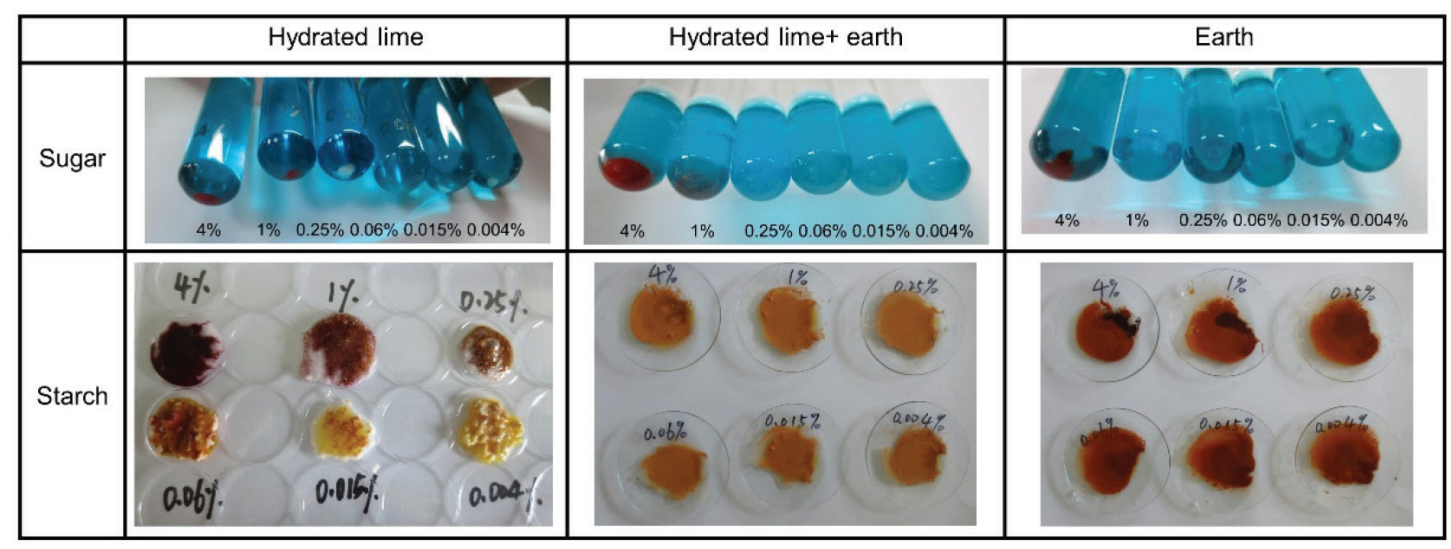

Figure 4. Results of chemical analyses on simulated brown sugar and sticky rice mortars with different inorganic binders

Table 1. Results of enzymatic analysis on lab-prepared mortar specimens (“+" for positive presence, and "--" for negative presence)

\begin{tabular}{|c|c|c|c|c|c|c|c|c|}
\hline \multirow{2}{*}{$\begin{array}{l}\text { Organic } \\
\text { additive }\end{array}$} & \multirow{2}{*}{$\begin{array}{c}\text { Inorganic } \\
\text { binder }\end{array}$} & \multicolumn{7}{|c|}{ Organic additive in mixing water $(\mathrm{w} / \mathrm{w})$} \\
\hline & & $4 \%$ & $1 \%$ & $0.25 \%$ & $0.06 \%$ & $0.015 \%$ & $0.004 \%$ & $0 \%$ \\
\hline \multirow{3}{*}{ Brown sugar } & Lime & + & + & + & + & - & - & - \\
\hline & Lime+ earth & + & + & + & - & - & - & - \\
\hline & Earth & + & + & + & - & - & - & - \\
\hline \multirow{3}{*}{ Sticky rice } & Lime & + & + & + & - & - & - & - \\
\hline & Lime+ earth & + & + & + & - & - & - & - \\
\hline & Earth & + & + & + & - & - & - & - \\
\hline
\end{tabular}


Table 2. Information of 11 historic mortar samples suspected to contain organic additives after chemical analysis

\begin{tabular}{|c|c|c|c|c|}
\hline Organic additive & Inorganic binder & Sample No. & Location & Year of construction \\
\hline \multirow{6}{*}{ Sugar } & \multirow{2}{*}{ Lime } & 1 & Jingzhou city wall (Hubei) & 1646 A.D. \\
\hline & & 2 & Kaifeng city wall (Henan) & $\sim 1842$ A.D. \\
\hline & \multirow{3}{*}{ Tabia } & 3 & Tiger Hill Pagoda (Jiangsu) & 959 A.D. \\
\hline & & 4 & Yude Building (Fujian) & 1636-1912 A.D. \\
\hline & & 5 & Tianfeigong Fort (Zhejiang) & $\sim 1717$ A.D. \\
\hline & Earth & 6 & Wuyun Building (Fujian) & 1567-1572 A.D. \\
\hline \multirow{5}{*}{ Starch } & \multirow{3}{*}{ Lime } & 7 & Tiger Hill Pagoda (Jiangsu) & 959 A.D. \\
\hline & & 8 & Quzhou city wall (Zhejiang) & 960-1279 A.D. \\
\hline & & 9 & Chang'an ship lock (Zhejiang) & 1129-1279 A.D. \\
\hline & \multirow{2}{*}{ Tabia } & 10 & Wang's residence (Zhejiang) & 1636-1912 A.D. \\
\hline & & 11 & Nanwan fort (Zhejiang) & $\sim 1888$ A.D. \\
\hline
\end{tabular}
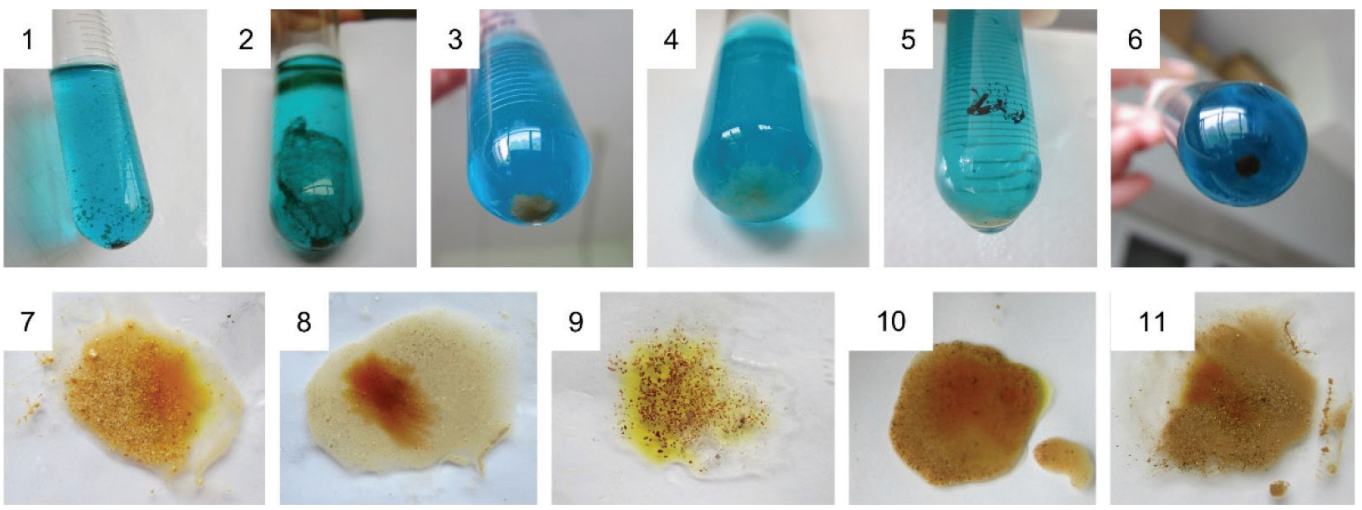

Figure 5. Results of historic mortar samples analyzed by chemical method (historic samples no. 1-11)

further study is needed to distinguish polysaccharides and sucrose in the tabia mortar sample from Tiger Hill Pagoda.

\section{FTIR}

To verify the results of chemical analyses, the historic mortar samples were analyzed by FTIR (Figure 6). The characteristic portlandite band (free $\mathrm{O}-\mathrm{H}$ stretching band at $\left.\sim 3642 \mathrm{~cm}^{-1}\right)^{23}$ is only present in the mortar samples of Jingzhou city wall (Figure 6a) and Chang'an ship lock (Figure 6b), indicating the still on-going carbonation of the lime mortars. The main calcite bands are centered at $2514\left[\mathrm{v} 1\left(\mathrm{CO}_{3}{ }^{2-}\right.\right.$ symmetric stretching $)+\mathrm{v} 3\left(\mathrm{CO}_{3}{ }^{2-}\right.$ asymmetric stretching) and/or $(2 v 2+v 4)], \sim 1796(v 1+v 4$ (C-O in-plane bending)), 1422 (v3), 874 (v2 (O-C-O out-of-plane bending)) and $\sim 713 \mathrm{~cm}^{-1}(v 4) .{ }^{24-26}$ In the spectrum of earth, the absorption bands at $\sim 1097, \sim 1034$ and $\sim 1009 \mathrm{~cm}^{-1}$ can be attributed to asymmetric Si-O stretching, $\sim 798$ and $\sim 778 \mathrm{~cm}^{-1}$ to symmetric Si-O stretching, $\sim 694$ and $\sim 536 \mathrm{~cm}^{-1}$ to Si-O bending. ${ }^{27-29}$

For brown sugar (Figure 6a) and sticky rice (Figure $6 \mathrm{~b}$ ), the absorption bands at $\sim 1135 / 1155, \sim 1053 / 1078$ and $\sim 988 / 994 \mathrm{~cm}^{-1} \mathrm{can}$ be assigned to $\mathrm{C}-\mathrm{O}$ bond stretching in the $\mathrm{C}-\mathrm{OH}$ group as well as the $\mathrm{C}-\mathrm{C}$ bond stretching in carbohydrate backbone structure, and the band at $\sim 922 / 925 \mathrm{~cm}^{-1}$ may be due to $\mathrm{C}-\mathrm{H}$ stretching of carbohydrate. ${ }^{30-32}$ For the lime mortar samples suspected to contain sugar (Jingzhou city wall and Kaifeng city wall), no absorption bands can be distinguished, which is similar to the spectrum of pure hydrated lime (Figure 6a), so the presence of sugar in these samples can be denied. As for the lime mortars suspected to contain sticky rice (Tiger Hill Pagoda, Quzhou city wall, Chang'an ship lock), one broad band was shown centered at $\sim 1000 \mathrm{~cm}^{-1}$ (Figure $6 \mathrm{~b}$ ), which confirms the presence of starch.

As for the historic samples containing earth (tabia and earth), however, the $\mathrm{SiO}_{2}$ in earth also has absorption bands between 1100$1000 \mathrm{~cm}^{-1}$, which overlapped the bands of brown sugar and sticky rice, thus making it difficult to identify sugars and starch in mortars.

\section{Enzymatic methods}

After enzymatic analysis on sucrose (Table 3), only 1 historic sample turned out to contain sucrose - earth mortar from Wuyun Building (Fujian) - which was in accordance with the literature records that brown sugar was usually added in mortars to build forts and vernacular dwellings in eastern and southeastern China. ${ }^{8-12}$ The results of enzymatic analyses also denied the presence of sucrose in Tabia from Tiger Hill Pagoda, suggesting that the positive result of chemical analysis was probably indeed brought by plant stems in the mortar (Figure 2S). As for the analysis on starch, 4 out of 5 samples gave positive results, which confirms the credibility of the iodinestarch chemical method.

The 5 mortar samples which were suspected to contain sucrose or starch according to the enzymatic analysis were further analyzed by SEM (Figure 7). The earth mortar from Wuyun Building (sample no. 6) had the most compact microstructure among all samples, which can be due to the rammed earth craftsmanship, and/or due to the addition of organic additives. Although lime is present in samples no. 7, 8, 9 and 11, no distinct rhombohedral crystals of calcite were found in their micrographs. Particularly, in pure lime mortar samples no. 7-9 which were suspected to contain sticky rice, calcium carbonate in subrounded shapes are observed, which is in accordance with the reports from other studies on lime mortars with sticky rice addition. ${ }^{16,33,34}$ Additionally, samples no. 7 and 8 seem to have smaller particles and less porous structures than samples no. 9, which might indicate the differences in the amount of sticky rice present in the samples. 

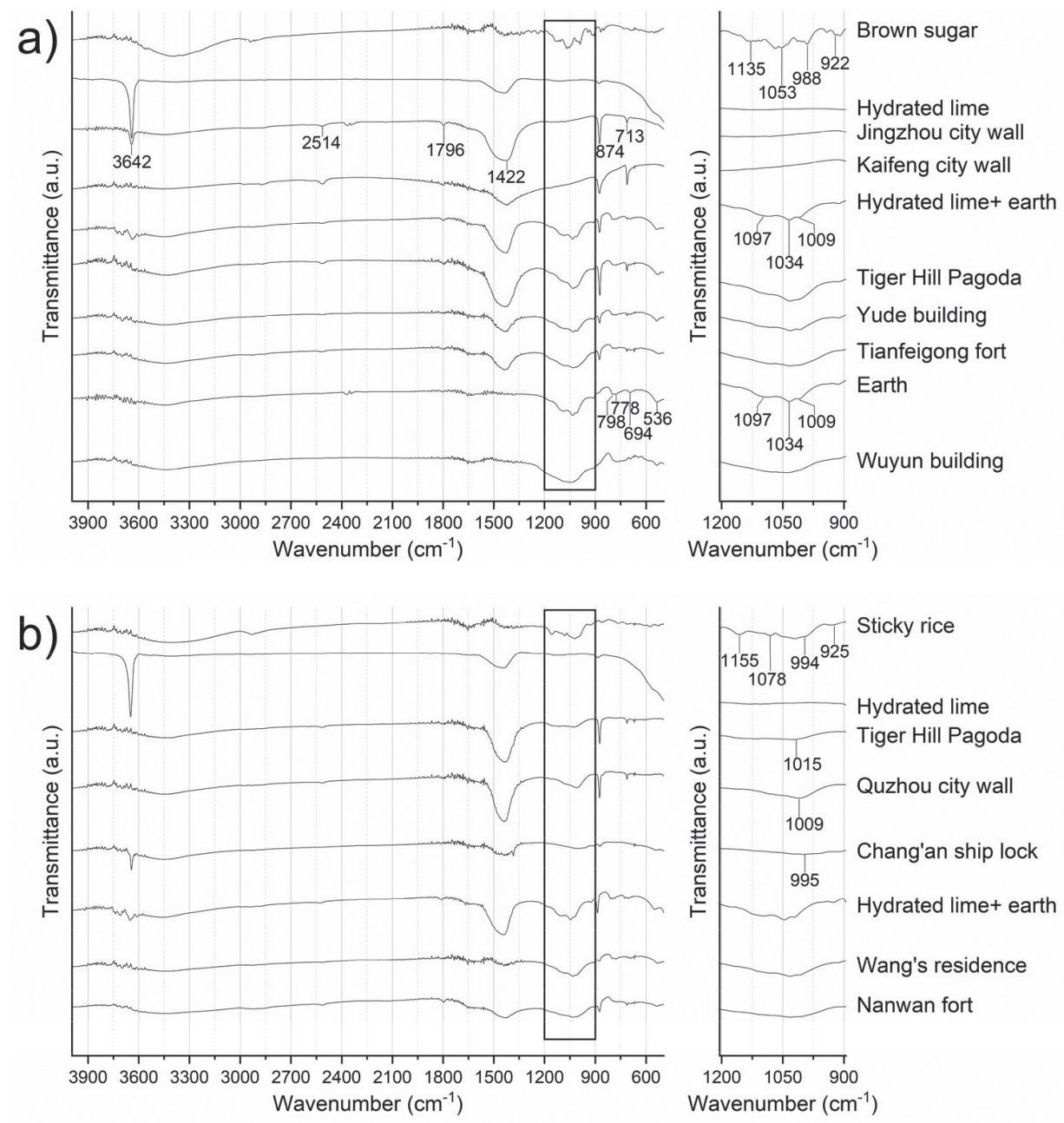

Figure 6. FTIR spectra of historic mortar samples suspected to contain brown sugar (a) and sticky rice(b)

Table 3. Results of enzymatic analyses on historic mortar samples ("+" for positive presence, and "-" for negative presence)

\begin{tabular}{lcccc}
\hline $\begin{array}{l}\text { Suspected } \\
\text { organic additive }\end{array}$ & $\begin{array}{c}\text { Inorganic } \\
\text { binder }\end{array}$ & \multicolumn{2}{l}{ Historic mortar sample No. } \\
\hline \multirow{3}{*}{ Brown sugar } & Lime & 1 & 2 & \\
\cline { 2 - 5 } & Lime+ earth & 3 & 4 & 5 \\
\cline { 2 - 5 } & Earth & 6 & - & - \\
\hline \multirow{3}{*}{ Sticky rice } & Lime & 7 & 8 & 9 \\
\cline { 2 - 5 } & & + & + & + \\
& & + & 11 & \\
\hline
\end{tabular}

\section{CONCLUSIONS}

For lab-prepared brown sugar mortars, the percentages of brown sugar addition above which the enzymatic method was able to detect were $0.06,0.25$ and $0.25 \%$ for mortars with inorganic binders of lime, lime+earth and earth, respectively. The results suggested that for brown sugar mortar analysis, enzymatic method was more sensitive and exclusive than chemical method (1,1 and 4\%), and particularly had higher detection capacity in lime mortars. For sticky rice mortars, enzymatic analysis was able to identify sticky rice addition above $0.25 \%$ in mortars with all inorganic binders. Compared with the chemical method results, the enzymatic analysis was less sensitive in mortars with lime as the sole binder ( $0.004 \%$ by chemical method), but more sensitive in mortars containing earth ( 4 and $1 \%$ by chemical method).

Chemical methods were applied on 45 historic mortar samples collected from 9 provinces with different inorganic binders (lime, tabia (lime+ earth) and earth), and 11 samples from 5 provinces gave positive results. FTIR analyses denied some false-positive results from chemical analyses on historic mortar samples with lime as binder, but when earth was present in mortar, it was impossible to identify absorption peaks of saccharides since they overlapped with the peaks of $\mathrm{SiO}_{2}$ in the earth. The enzymatic analysis successfully identified sucrose in 1 sample, distinguished sucrose from polysaccharides (plant stem) in another sample and denied false-positive chemical results in the other 4 samples. For the analysis on mortars with possible presence of sticky rice, 4 out of 5 samples gave positive results. The results from the enzymatic analysis were further corroborated by SEM, which showed calcium carbonate in sub-rounded shapes in the samples.

To sum up, this study showed that compared with common chemical and FTIR analyses, enzymatic method was more sensitive and exclusive for sucrose analysis in both lime- and earth-based mortars, and for starch analysis in earth-based mortars. Therefore, it could be applied as a complementary analysis method of organic additives in historic mortars. 

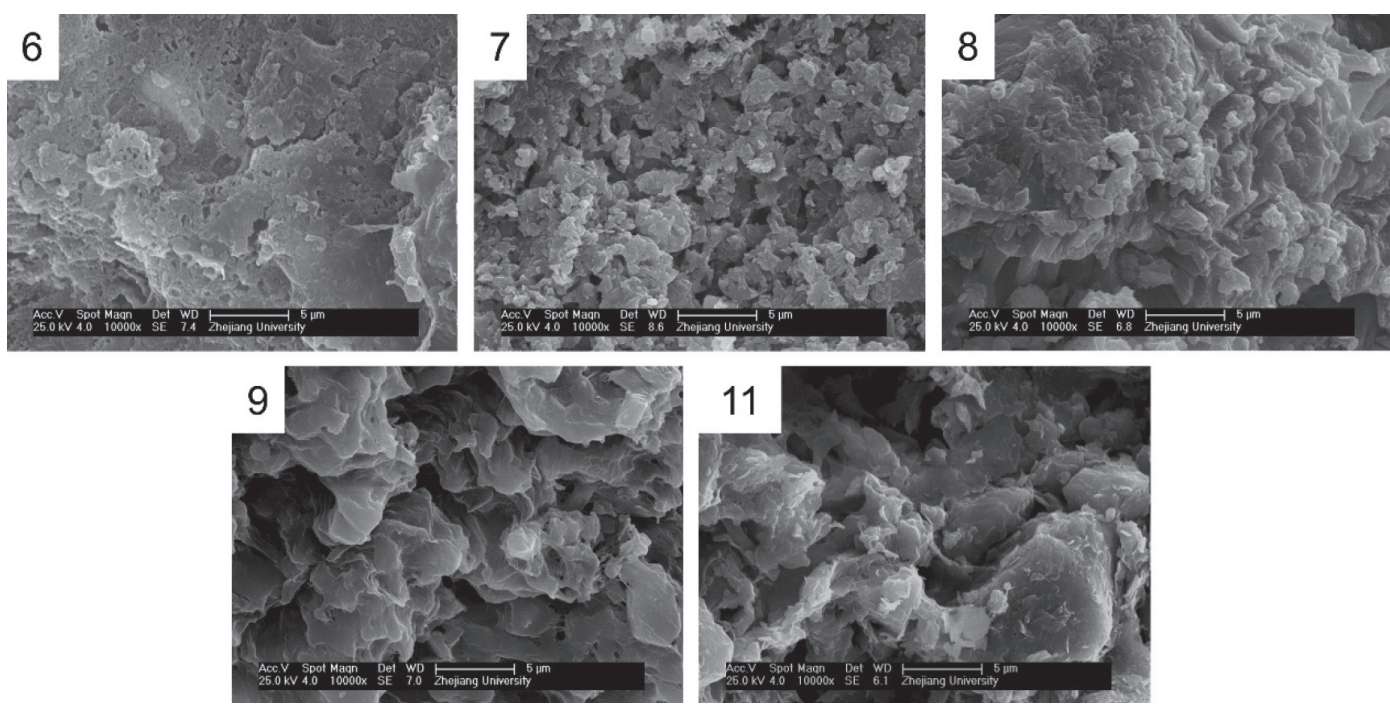

Figure 7. Microstructure of the internal bulk of historic mortar samples (6. earth mortar from Wuyun building; 7. lime mortar from Tiger Hill Pagoda; 8. lime mortar from Quzhou city wall; 9. lime mortar from Chang'an ship lock; 11. tabia mortar from Nanwan fort)

\section{SUPPLEMENTARY MATERIAL}

Figures 1S-2S and Table 1S are freely available at http:// quimicanova.sbq.org.br in pdf format.

\section{ACKNOWLEDGEMENTS}

This research was funded by the China Postdoctoral Science Fund under Grant [number 2018M630660].

\section{REFERENCES}

1. Baronio, G.; Binda, L.; Lombardini, N.; Constr. Build. Mater. 1997, 11, 33.

2. Rodriguez-Navarro, C.; Hansen, E.; Ginell, W. S.; J. Am. Ceram. Soc. 1998, 81, 3032.

3. Seabra, M. P.; Paiva, H.; Labrincha, J. A.; Ferreira, V. M.; Constr. Build. Mater. 2009, 23, 1147.

4. Moropoulou, A; Bakolas, A.; Moundoulas, P.; Aggelakopoulou, E.; Anagnostopoulou, S.; Cem. Concr. Compos. 2005, 27, 289.

5. Lanas, J.; Álvarez-Galindo, J. I.; Cem. Concr. Res. 2003, 33, 1867.

6. Gwilt, J.; The Architecture of Marcus Vitruvius Pollio: in Ten Books, $1^{\text {st }}$ ed., Lockwood \& Co.: London, 1874

7. Bostock, J.; Riley, H. T.; The Natural History of Pliny, $1^{\text {st }}$ ed., Henry G. Bohn: London, 1857.

8. Qian, Z.; Cheng Shou Chou Lve, Qian Modang ed., 1644.

9. Ming, Z.; Sang Yuan Wei Zong Zhi, Xihu district Fuwen building ed., 1870 .

10. Du, F.; Historic Research on Kaiping Diaolou of Guangdong (in Chinese), Tsinghua University, China, 2005.

11. Li, X.; Industrial Architecture 2006, 36, 61.

12. Pang, F.; Research on Characteristics of Chronological Order of Gulangyu Architecture (in Chinese), Xi'an University of Architecture and Technology, 2007.

13. Li, J.; Zhang, B.; Journal of Archaeological Method and Theory 2019, 26,502 .
14. Dai, M.; Research and reproduction of traditional Chinese organic tabia (in Chinese), Ocean University of China, China, 2014.

15. Zhang, K.; Zhang, H.; Fang, S.; Li, J.; Zheng, Y.; Zhang, B.; Archaeometry 2014, 56, 100.

16. Yang, F.; Zhang, B.; Ma, Q.; Acc. Chem. Res. 2010, 43, 936

17. Fang, S.; Zhang, H.; Zhang, B.; Zheng, Y.; J. Cult. Herit. 2014, 15, 144.

18. Montana, G.; Ronca, F.; J. Cult. Herit. 2002, 15, 133.

19. Rao, H.; Li, B.; Yang, Y.; Ma, Q.; Wang, C.; Anal. Methods 2015, 7, 143.

20. Bersani, D.; Lottici, P. P.; Antonioli, G.; Campani, E.; Casoli, A.; Violante, C.; J. Raman Spectrosc. 2004, 35, 694.

21. Rampazzi, L.; Colombini, M. P.; Conti, C.; Corti, C.; Lluveras-Tenorio, A.; Sansonetti, A.; Zanaboni, A.; Archaeometry 2016, 58, 115.

22. Birstein, V. J.; Stud. Conserv. 1975, 20, 8.

23. Paz, S. P. A.; Angélica, R. S.; Neves, R. F.; Quim. Nova 2010, 33, 579.

24. Gunasekaran, S.; Anbalagan, G.; Pandi, S.; J. Raman. Spectrosc. 2006, 37, 892 .

25. Santos, L. F.; Santos, A. L. A.; Rocha, S. D. F.; Quim. Nova 2017, 40, 720.

26. Miliani, C.; Rosi, F.; Daveri, A.; Brunetti, B. G.; Appl. Phys. A 2012, 106, 295.

27. Anbalagan, G.; Prabakaran, A. R.; Gunasekaran, S.; J. Appl. Spectrosc. 2010, 77, 86.

28. Saikia B.; Parthasarathy, G.; Sarmah, N. C.; Bull. Mater. Sci. 2008, 31 , 775 .

29. Gardolinski, J. E.; Martins-Filho, H. P.; Wypych, F.; Quim. Nova 2003, $26,30$.

30. Anjos, O.; Campos, M. G.; Ruiz, P. C.; Antunes, P.; Food Chem. 2015, 169,218

31. Paradkar, M. M.; Sakhamuri, S.; Irudayaraj, J.; J. Food Sci. 2002, 67, 2009.

32. Osorio, C.; Carriazo, J. G.; Barbosa, H.; Quim. Nova 2011, 34, 636.

33. Zhao, P.; Jackson, M. D.; Zhang, Y.; Li, G.; Monteiro, P. J. M.; Yang, L.; Constr. Build. Mater. 2015, 84, 477.

34. Zeng, Y.; Zhang, B.; Liang, X.; Sciences of Conservation and Archaeology 2008, 2, 1. 